\title{
A review on the bond behavior of FRP composites applied on masonry substrates
}

\author{
Alessandro Bellini ${ }^{a^{*}}$, Claudio Mazzotti ${ }^{a, b}$ \\ ${ }^{a}$ CIRI Buildings and Construction, University of Bologna, Via del Lazzaretto 15/5, 40131, Bologna, Italy \\ ${ }^{\mathrm{b}}$ DICAM, University of Bologna, Viale Risorgimento 2, 40136, Bologna, Italy
}

Received: 06 November 2017 / Accepted: 28 December 2017 / Published online: 30 December 2017

(C) The Author(s) 2017. This article is published with open access and licensed under a Creative Commons Attribution 4.0 International License.

\begin{abstract}
The need of repairing and retrofitting masonry buildings, typical of Italian and European built heritage, determined a growing interest towards the development of effective and cost efficient innovative strengthening solutions. Among the different techniques currently available, the adoption of composite materials, such as Fiber Reinforced Polymers (FRPs), proved to be one of the most viable solutions for the strengthening of masonry structures. If not properly fixed, a common failure mode of this system is the early debonding of the reinforcement from the substrate. For this reason, several experimental tests and numerical analyses are currently available in the literature, clarifying and predicting the bond behavior of FRP glued to masonry substrates. The purpose of this paper is to provide an overview of the results obtained by the different experimental works, of the numerical analyses performed both for evaluating and validating experimental results and of the simplified analytical models currently available for the prediction of the maximum capacity of the strengthening systems. Results of extended experimental campaigns, carried out also within different Round Robin Test (RRT) series, with several laboratories involved, and recent model calibrations will be discussed together with the approach proposed by the actual guidelines.
\end{abstract}

Keywords: FRP; Masonry; Bond; Experimental test; Numerical analyses

\section{Introduction}

The use of Fiber Reinforced Polymers (FRPs) for the strengthening of reinforced concrete and masonry structures has emerged, during the last decades, as a competitive alternative to traditional strengthening techniques [1-7]. The key advantages of advanced composite materials applied to civil engineering are basically their high mechanical properties and lightness, which allow to obtain very competitive strength-to-weight and stiffness-to-weight ratios. The application of FRP composite materials started in reinforced concrete structures, where their use proved to be very effective for flexural and shear strengthening of RC beams and confinement of columns and it was later extended to masonry and wood structures $[2,3,8]$.

Masonry buildings, in particular, represent a large percentage of Italian and European built heritage, and their vulnerability has dramatically emerged one seismic event after the other, with severe damages and partial or total collapses. In this framework, the use of FRPs for strengthening masonry constructions is one of the most promising solutions, especially when a proper knowledge of their mechanical behavior is considered. In particular, an early failure of the system can be observed due to the debonding of the reinforcement from the substrate, before reaching the tensile strength. For this reason, the FRPmasonry bond behavior has been deeply investigated in recent years.

The present paper is aimed at providing a review of the experimental works available in the literature on FRPmasonry bond, in order to describe the interface behavior, the possible failure modes, the load bearing capacity and parameters affecting these aspects. Results coming from different Round Robin Test activities, carried out by different laboratories and universities [9-11], will also be discussed, in order to critically investigate similarities and differences coming from experimental outcomes.

A brief overview of the numerical analyses available will also be presented, focusing the attention on the numerical aspects allowing for a reliable description of the failure mechanisms which typically occur during bond tests and on the most appropriate interface laws able to properly describe the debonding process. Finally, the most recognized analytical models for the prediction of the FRP system bond

\footnotetext{
* Corresponding author: Alessandro Bellini, E-mail: alessandro.bellini5@unibo.it
} 
strength will be classified and the results of their calibration will be presented, with particular attention to the approach proposed by the current Italian guidelines [12].

\section{Experimental tests}

In the following, a brief overview of the key aspects characterizing the experimental tests developed so far to investigate the bond between FRP and masonry substrate will be presented, together with the main results in terms of global and local behavior.

\subsection{Set-up}

In order to acquire a proper knowledge of the bond behavior of FRP composite materials when applied on masonry substrates, experimental bond tests have been carried out by several authors, working on single bricks or on masonry panels specimens [9-11, 13-39].

The possible experimental set-ups suitable for bond tests have been originally collected and classified in [40], having in mind tests on concrete substrates. Among these systems, the set-ups mainly used for shear bond tests on masonry are the single-lap and the double-lap ones. In particular, the single-lap push-pull set-up proved to effectively overcome the main drawbacks of the double-lap set-up, such as two different substrates where FRP was applied, not symmetrical failure, uncertainty in assessing a symmetric redistribution of the external applied load between the two faces. It is actually the most common set-up used for bond tests on masonry substrates. The main concern when using this arrangement is to guarantee a perfect alignment between the axis of the FRP reinforcement and the axis of the head of the testing machine, in order to avoid potential stresses perpendicular to the interface (peeling stresses). Even if a perfect alignment of the set-up is assured, bending effects can develop in single-lap shear set-up (as in the double-lap scheme) because of the distance between the axis where the load is applied and the midsection of the sample where the reaction is delivered.

Experimental bond tests can be found in literature on both single bricks and masonry specimens, the latter being a variable number of bricks separated by mortar joints. The FRP bonded part usually starts few centimeters away from the front-edge of specimen in order to avoid or minimize the effect of unbalanced traction forces leading to an early detachment of the substrate. Tests are carried out mainly under displacement control. Displacement transducers (LVDTs or potentiometers) have been used for monitoring the slip between the reinforcement and the substrate during the test, whereas strain gauges or innovative techniques (such as Digital Image Correlation [28, 33, 37, 39, 41, 42]) allowed to analyze local strain distributions during the debonding process. Results of bond tests have been analyzed and discussed in terms of load-slip curves, strain distributions, and, when possible, interface laws experimentally determined.

\subsection{Failure modes}

Experimental studies showed that debonding from the substrate is the most common failure mode of FRP composite materials applied on masonry, with very few cases of adhesive failure or tensile rupture of the reinforcement [9-11, 25-28, 31, 33, 34].

An analysis of the bond behavior of GFRP strips applied on modern and historic brickwork masonry is presented in [24], where it was confirmed that composite materials bonded to historic brick masonry manifest a typical debonding failure. Studies presented in $[13,43]$ clarified that SRP strips are also an effective and alternative solution to FRPs for strengthening historic masonry.

Experimental works on FRP composite materials bonded to historic masonry are also discussed in [16, 27]: results showed that GFRP reinforcement usually reveals a cohesive debonding failure with detachment of a thin layer of substrate, usually thicker in correspondence of the mortar joints. The failure mechanism of ancient masonry elements when strengthened by CFRPs is properly analyzed in [25], where the debonding mechanism was divided into two main typical failure modes: a first mode characterized by a thick and irregular layer of substrate detached with a wedge of masonry at the free end and a second failure mode with a thinner layer of detached materials, both related to the penetration depth of the glue into the substrate. Experimental analyses were also conducted in [19] on masonry stones reinforced with CFRPs, concluding that the type of substrate has a great influence on the bond capacity, not only in terms of mechanical properties, but also in terms of other physical properties. Advanced studies carried out on masonry panels made of clay bricks strengthened with GFRPs [29, 30, 32] confirmed that taking into account only mechanical properties and not considering brick anisotropy or physical properties such as porosity and surface roughness cannot lead to a correct estimation of the bond capacity; in this framework, the analyzed physical and mechanical properties can also explain different penetration depth for different substrates.

Extended experimental campaigns on the same substrate material (single bricks or masonry panels) strengthened with different types of FRPs, carried out within different RILEM Round Robin Test (RRT) series [9, 10], involving several laboratories and universities, confirmed the typical failure modes highlighted by the other authors with a predominance of the cohesive debonding of the composite material from the substrate with a thin layer of detached material (Fig. 1). Tests performed on masonry panels presented, in general, a thicker layer of material detached in correspondence of the mortar joints.

The use of matrices different from the classic epoxy resin [11], characterized by the presence of a highly deformable polymer, lead to a slightly different failure mode, with a larger redistribution of the shear stresses over the bonded area during the debonding process and a final failure where the detachment of a thick layer of material occurred. 


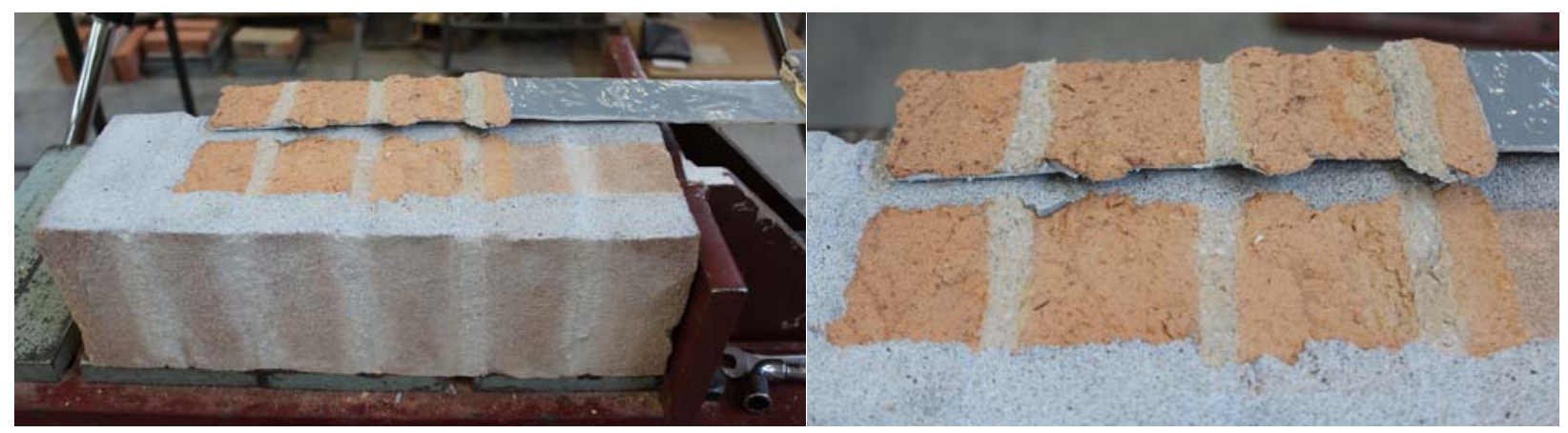

Figure 1. Typical failure mode: debonding of FRP reinforcement from the substrate.

Debonding failure was also detected as the main failure mode during bond tests on tuff elements strengthened with FRP composites [26, 34].

\subsection{Global results: force-slip curves}

Experimental data made available from the tests were first analyzed by the different authors in terms of bond capacity and load-slip curves, taking into account also the role of mortar joints in the transition from bond tests on single bricks/stones to bond tests on masonry elements. An example of load-slip curves obtained by bond tests on single bricks and on masonry panels is presented in Fig. 2.

The typical behavior of FRP composites applied on masonry substrates, when analyzing force-slip curves, considering bond lengths longer than the effective one, is mainly described by an ascending almost linear branch until the onset of debonding process, followed by a nearly horizontal plateau $[10,14,25,27]$ up to the complete detachment of the composite reinforcement. This behavior could be defined as similar to that observed on bond tests performed on concrete substrates. Nevertheless, when load-slip curves coming from bond tests on bricks and on masonry prisms are compared, a significant difference can be found between these two types of substrates. In fact, experimental curves obtained from masonry prisms presented several discontinuities or jumps during the debonding part of the tests, with a typical saw-tooth shaped curve, where load drops are associated with the periodic alternation of bricks and mortar joints on the substrate [10, 27, 44-46]. This particular behavior was mainly observed analyzing load-slip curves and confirmed by local strain gauges readings during tests execution; several numerical models [39, 44, 47-49] were then developed in order to validate experimental outcomes and to better understand this phenomenon, assuming different interface laws for bricks and mortar joints.

Comparing maximum debonding forces $[10,27,33]$, the capacity seems to generally increase moving from single bricks to masonry prisms. This aspect may be partially related to an additional interlocking effect provided by mortar joints, but it was found to be also strictly linked to the mechanical and physical properties of the substrate: anisotropy of the brick (different faces used), porosity and surface roughness [29, 30, 32].

Other studies [28] were carried out with the purpose of investigating the role of inclination between mortar joints and FRP reinforcements, concluding that the overall bond strength was almost not affected by mortar joints inclination or by some specific wall textures, which caused only local variations of the strain field but no significant changes on the maximum bond capacity.

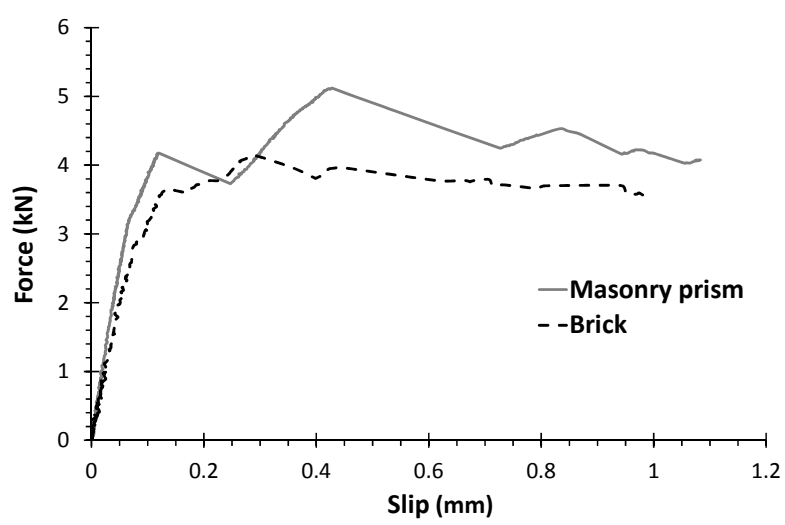

Figure 2. Examples of load-slip curves obtained during bond tests on single bricks and on masonry prisms.

\section{$2.4 \quad$ Strain profiles}

The bond behavior of FRP composite materials cannot be fully described without analyzing strain distribution during the debonding process. To this purpose, deformations were measured within the bonded area of the reinforcements by most of the authors, using traditional strain gauges [9-11, 13, $14,16,19,23,24,27,50]$ or innovative measurement techniques, such as Digital Image Correlation [28, 41-43, 45]. An example of a typical strain distribution is reported in Fig. 3 for increasing values of applied force and during the debonding process.

From a qualitative point of view $[13,14,19,27]$, strain distributions were found to be quite similar to those typical of FRP-concrete interface [51], both for brick and masonry panels, with an exponential decay type distribution registered for low load levels followed by a S-shaped 
distribution after the onset of the debonding process. The analysis of strain distributions was very useful for identifying the portion of substrate involved in the shear transfer process during debonding and for estimating the effective bond length of the reinforcements tested. Experimental studies carried out by different authors on single bricks and masonry panels reinforced with several types of FRP composite materials pointed out that, as highlighted in [27], axial strain profiles are useful to clarify that load drops identified in load-slip curves of masonry panels are related to the crossing of mortar joints during the debonding process.

The analysis of axial strain profiles was used in [11] to identify the bond behavior of glass, basalt, carbon and steel textiles re-applied (after the original debonding) on masonry panels by means of an highly deformable polymer. Strain distributions confirmed the capability of more deformable matrices to redistribute shear stresses over a longer bonded area, avoiding local concentrations, which may activate the debonding process.

The application of Digital Image Correlation technique instead of using strain gauges, allowed many authors [18, 28, $41,42,45]$ to fully analyze strain distributions not only in pre-assigned points but covering the whole investigated area, obtaining a more uniform description by means of complete $2 \mathrm{D}$ or $3 \mathrm{D}$ maps. In more detail, the experimental study described in [28] revealed local variations of the strain pattern when analyzing FRP composite materials applied on masonry substrates with an inclination with respect to the mortar joints, even if the effect was found to be not significant on the global force-slip behavior.

The application of DIC technique in investigating the tensile and bond behavior of FRP composites [41] allowed the authors to useful evaluate the three-dimensional aspects coming from shear bond tests, analyzing also strain transversal distribution and properly characterizing bond-slip laws.

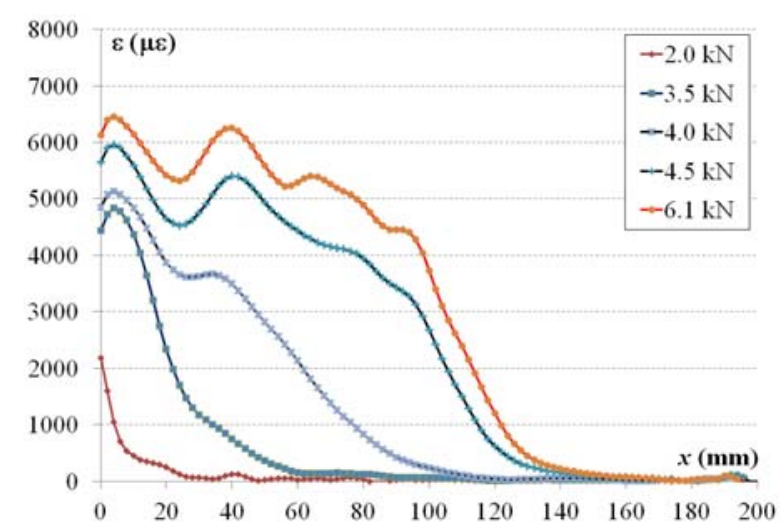

Figure 3. Example of strain profiles measured during an experimental bond test performed on masonry prisms strengthened with GFRP (by using DIC technique).

DIC application to composite reinforcements testing was also validated in [42], pointing out the possibilities and additional information provided by this technique in tensile and bond tests: in particular, the evaluation of strain profiles during shear tests suggested that the load transfer mainly takes place between the reinforcement and the bricks and that the bricks of the masonry prisms are suddenly involved in the load transfer mechanism as soon as shear stresses crosses a mortar joint. This study represents a further confirmation of the role of the mortar joints that clearly influenced the global and local behavior of FRPs when applied on masonry panels and not only on single bricks.

The effect of the periodic pattern of bricks and mortar joints on the stress transfer was deeply analyzed in [45]: the study pointed out that the transferable load at the FRP-masonry interface varies periodically and that equals the FRP-brick bond capacity only if the length of the brick in the fibers direction is greater than the effective bond length of the FRP-brick interface.

As highlighted by many authors, strain distribution analysis is very important to experimentally assess appropriate interface laws useful to describe the debonding phenomenon and to calibrate numerical and predictive models.

\subsection{Local interface laws}

The shear transfer mechanism occurring during debonding between the FRP reinforcement and the masonry substrate can be properly described by means of appropriate local interface laws. Starting from experimental strain profiles, it is possible to calibrate non-linear shear stress-slip laws able to describe the bond behavior of the samples subjected to bond tests.

Different approaches can be used, based on inverse analyses [52] or more simple calibration techniques [53], with a postprocessing of experimental strain recorded along the FRP reinforcement. Another example concerning the assessment of appropriate shear force-slip relationships, assuming a function for approximating experimental strain profiles, can be found in [54].

Results of interface laws calibrations can be found in different studies [9, 13-16, 19, 23-25, 27, 41, 55] and have been very useful as a first step to define parameters for performing accurate numerical analyses [44, 56-59], even at larger scales.

Fig. 4 shows the typical shape of a local shear stress-slip curve obtained by post-processing experimental data. It is characterized by an almost linear ascending branch up to the maximum registered shear stress and by a following postpeak softening branch, which is non-linear for growing values of slips. The area below the points represents the fracture energy of the cohesive interface and it is strictly related to the bond capacity of the reinforcement.

The numerical local interface laws generally used to fit the experimental results have a curvilinear shape [27] or a bi-, tri, or quadri-linear shape [56], being the bilinear the most common one, as it proved to be able to provide, in most cases, satisfactory results if the correct value of fracture energy is used. 


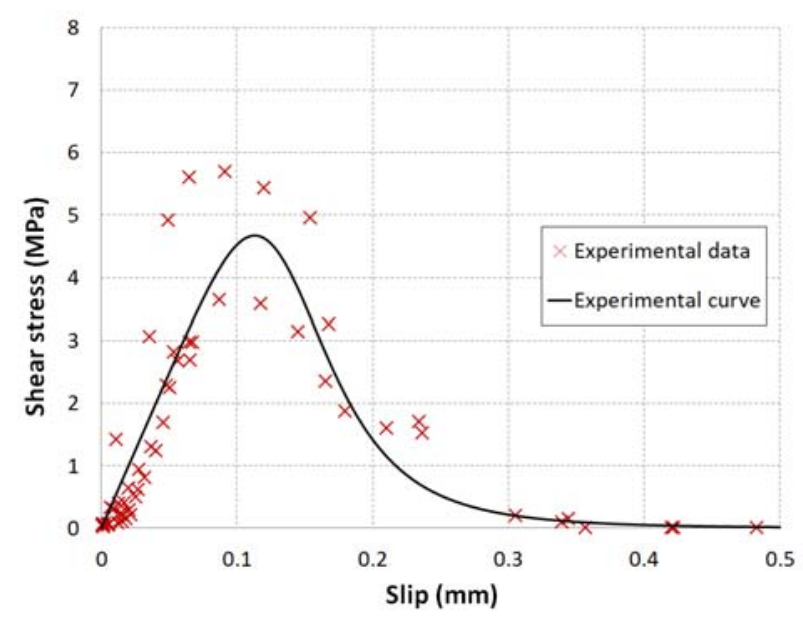

Figure 4. Experimental shear stress-slip data and corresponding calibrated interface law.

\section{Numerical simulations}

The bond behavior of FRP composite materials applied on masonry panels has been numerically evaluated by several authors. Studies on masonry elements reinforced by FRPs have been carried out by means of finite element (FE) models, considering the case of perfect adhesion and modelling mortar and bricks independently [60] or considering also the three-dimensional effects induced by FRP debonding and evidenced by DIC during experimental tests [57]. A detailed and critical comparison between two different fully three-dimensional FE models is presented in [58], where a model in which only masonry is damageable and FRP reinforcement perfectly adheres to the substrate is compared with an alternative model in which a cohesive zero-thickness damage interface between FRP and masonry is considered.

Starting from the experimental results, a trilinear bond-slip model is proposed for the interface elements in [61], with a comparison between numerical and experimental results for a better understanding of the failure mechanisms. Another numerical study [49] was aimed at evaluating the role of mortar joints in the bond behavior of FRP composite materials, critically discussing the presence of mortar joints with different mechanical properties.

A simple approach was proposed in [62], introducing a bond strength degradation when the debonding process crosses mortar joints, in good agreement with experimental data. Similarly, in [59] the load drops obtained during experimental bond tests were reproduced numerically by taking into account the role of mortar joints in the shear stress transfer process.

A different numerical FE model, described in [44], was developed making use of two different interface laws in order to evaluate the role of mortar joints (Fig. 5). It allowed to properly capture the behavior of GFRP composite reinforcements applied on four different types of masonry substrates, in terms of global and local response, confirming that load drops during the debonding phase are associated to jumps of the FRP effective bonded part across mortar joints.

The effect of the shape of the cohesive material law adopted on the stress transfer at FRP-masonry interface is discussed in detail in [56], where the authors concluded that the adoption of bi-, tri, or quadri-linear interface laws with the same fracture energy and effective bond length does not lead to significant variations in the maximum transferable load.

Advanced non-linear simulations of experimental test results [63], performed on FRP sheets applied on historic masonries and carried out by using zero-thickness interface elements, showed that cohesion and shear fracture energy are the most important parameters on FRP-masonry interfacial behavior and that the ultimate load and the effective bond length can be assessed through numerical analyses.

A simulation of the bond behavior of tuff elements reinforced with FRPs, carried out using an analytical model and two (bi- and three-dimensional) FE models is critically discussed in [64], concluding that, whereas the monodimensional approach can provide fast reliable information and the three-dimensional one can provide more details about local stress distributions, the bi-dimensional model seems the best compromise.

Other important issues for understanding the debonding phenomenon of FRP composites from concrete and masonry substrates, such as the size and width effects, have been deeply studied and clarified in [37,65, 66].

Numerical and analytical models have also been proposed for the analysis of the bond behavior of FRP composite materials applied on curved substrates [35, 36, 67, 68], such as arches and vaults.

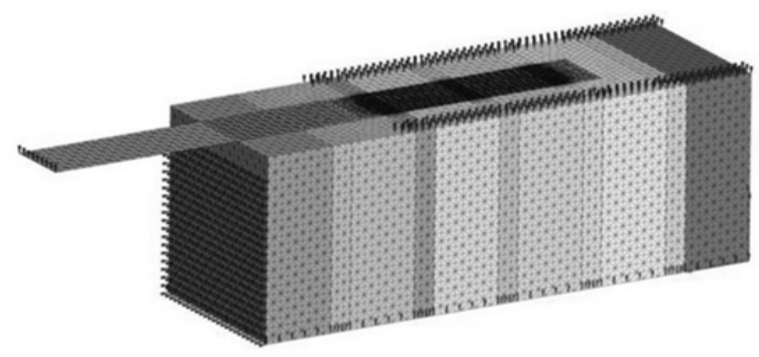

Figure 5. Example of a FE model mesh used for numerical simulation [44].

\section{$4 \quad$ Bond strength models}

In concrete and masonry substrates strengthened with externally bonded FRPs, the bond behavior at the extremity of the reinforcement is similar to what revealed during bond tests, where interfacial shear stress are predominant and normal stresses can be neglected (when flat substrates are considered). Starting from this assumption, several formulations have been proposed so far for estimating the debonding force in concrete [12, 40, 69-73]. An overview of the existing bond strength models mainly proposed for concrete, but which can also be used for masonry 
substrates, is presented in [74, 75]; the most common models with the relative references are summarized in Table 1.

The approaches adopted by CNR Italian Guidelines [12], Japanese Society of Civil Engineers guideline [76], ACl 440.2R-08 [77] and Fib Bulletin 14 [78] are discussed in [75], whereas reliability and adaptability of analytical models proposed for FRP composites to Steel Reinforced Polymer (SRP) systems is evaluated in [79].

The assessment of a bond strength model for FRPs externally bonded over masonry is described in detail in [80, 81]. These papers explain the direct correlation between FRP-masonry bond strength and the main concepts of cohesive fracture mechanics, which are the basis of design criteria used in [12]. Authors also perform a calibration of the $k_{G}$ coefficient contained inside the current formulation for the maximum debonding force adopted by Italian Guidelines, which reads:

$$
F_{\text {max }, d}=b_{f} \sqrt{2 E_{f} t_{f} k_{b} k_{G} \sqrt{f_{b c} f_{b t}}}
$$

where $f_{b c}$ and $f_{b t}$ are the mean brick compressive and tensile strength, $k_{b}$ and $k_{G}$ are corrective coefficients, $E_{f}, t_{f}$ and $b_{f}$ are, respectively, elastic modulus, thickness and width of the reinforcement.

Table 1. Bond strength models.

\begin{tabular}{ll}
\hline Model & Reference \\
\hline Tanaka & {$[71]$} \\
Sato & {$[82]$} \\
Iso & {$[82]$} \\
Yang & {$[82]$} \\
Neubauer and Rostasy & {$[83]$} \\
Willis & {$[14]$} \\
Kashyap & {$[15]$} \\
Maeda & {$[84]$} \\
Khalifa & {$[84]$} \\
De Lorenzis & {$[83]$} \\
Chen and Teng & {$[71]$} \\
Niedermeier & {$[75,85]$} \\
\hline
\end{tabular}

Starting from the proposed formulation (1), another calibration of design parameters, performed using experimental data collected during two different Round Robin Tests series $[9,10]$ and following the approach proposed in [80, 81], is discussed in [10].

A further calibration, based on an extensive database of results available in the literature and on new results of bond tests performed on three different types of masonry substrates very common in Italy, composed of tuff stones, Lecce stones and clay bricks, has been proposed in [34].
The proposed bond strength models take into account the debonding failure mechanism highlighted during experimental bond tests and, for this reason, mainly consider mechanical properties of the substrate. However, recent researches $[29,30,32]$ pointed out that taking into account only bricks mechanical properties is not sufficient to properly evaluate maximum debonding forces revealed during experimental tests. Other parameters, such as porosity and surface roughness, were found to play a crucial role in influencing the resin capacity to penetrate into the substrate and in determining the debonding load.

\section{Conclusions}

Structural strengthening of masonry structures with composite materials is becoming more and more an interesting and cost efficient solution for repairing and strengthening existing buildings, especially in seismic areas. In this framework, a proper knowledge of the bond behavior of FRP retrofitting systems when applied on masonry substrates is needed.

The paper presented (in short) the most important results of different experimental and numerical studies available in the literature aimed at evaluating the debonding phenomenon of FRP materials applied as external reinforcements to masonry structures. To this purpose, the most common setups used for bond tests have been described, analyzing experimental outcomes in terms of typical failure modes, force-slip curves, strain profiles and interface laws.

An overview of some numerical simulations performed by different authors in order to reproduce and validate the experimental bond behavior of the samples has been presented, focusing the attention on the role of the mortar joints on FRP debonding from masonry.

The most common bond strength models have been also presented, together with the approach used within actual guidelines and the results of more recent calibrations.

Results of extended experimental campaigns, carried out also within different Round Robin Test (RRT) series, have been discussed and were found to be very useful to calibrate predictive formulas needed at design level for the estimation of the maximum capacity of the reinforcements.

\section{Acknowledgements}

The financial support of the Italian Department of Civil Protection (ReLUIS 2017 Grant - Innovative Materials) is gratefully acknowledged.

\section{References}

[1] H. Saadatmanesh, Extending service life of concrete and masonry structures with fiber composites. Construction and Building Materials (1997) 11: 327-335. https://doi.org/10.1016/S0950-0618(97)00054-8

[2] T.C. Triantafillou, Composites: A new possibility for the shear strengthening of concrete, masonry and wood. Composites Science and Tecnhnology (1998) 58: 1285-1295. https://doi.org/10.1016/S0266-3538(98)00017-7 
[3] L. Van Den Einde, L. Zhao, F. Seible, Use of FRP composites in civil structural applications. Construction and Building Materials (2003) 17: 389-403. https://doi.org/10.1016/S0950-0618(03)00040-0

[4] N.G. Shrive, The use of fibre reinforced polymers to improve seismic resistance of masonry, Construction and Building Materials (2006) 20: 269-277. https://doi.org/10.1016/j.conbuildmat.2005.08.030

[5] L.C. Hollaway, A review of the present and future utilisation of FRP composites in the civil infrastructure with reference to their important in-service properties, Construction and Building Materials (2010) 24: 2419-2445. https://doi.org/10.1016/j.conbuildmat.2010.04.062

[6] S.A. Babatunde, Review of strengthening techniques for masonry using fiber reinforced polymers, Composite Structures (2017) 161: 246-255. https://doi.org/10.1016/i.compstruct.2016.10.132

[7] M.R. Valluzzi, Challenges and perspectives for the protection of masonry structures in historic centers: the role of inoovative materials and techniques, RILEM Technical Letters (2016) 1: 45-49. https://doi.org/10.21809/rilemtechlett.2016.10

[8] C.E. Bakis, L.C. Bank, V.L. Brown, E. Cosenza, J.F. Davalos, J.J. Lesko, A. Machida, S.H. Rizkalla, T.C. Triantafillou, Fiber-reinforced polymer composites for construction - State-of-the-art review, Journal of Composites for Construction (2002) 6(2): 73-87. https://doi.org/10.1061/(ASCE)1090-0268(2002)6:2(73)

[9] M.R. Valluzzi, D.V. Oliveira, A. Caratelli, G. Castori, M. Corradi, G. de Felice, E. Garbin, D. Garcia, L. Garmendia, E. Grande, U. lanniruberto, A. Kwiecień, M. Leone, G.P. Lignola, P.B. Lourenço, M. Malena, F. Micelli, M. Panizza, C.G. Papanicolau, A. Prota, E. Sacco, T.C. Triantafillou, A. Viskovic, B. Zając, G. Zuccarino, Round Robin Test for composite-to-brick shear bond characterization, Materials and Structures (2012) 45: 1761-1791. https://doi.org/10.1617/s11527-012-9883-5

[10] G. de Felice, M.A. Aiello, A. Bellini, F. Ceroni, S. De Santis, E. Garbin, M. Leone, G.P. Lignola, M. Malena, C. Mazzotti, M. Panizza, M.R. Valluzzi, Experimental characterization of composite-to-brick masonry shear bond, Materials and Structures (2016) 49: 25812596. https://doi.org/10.1617/s11527-015-0669-4

[11] A. Kwiecień, G. de Felice, D.V. Oliveira, B. Zając, A. Bellini, S. De Santis, B. Ghiassi, G.P. Lignola, P.B. Lourenço, C. Mazzotti, A. Prota, Repair of composite-to-masonry bond using flexible matrix, Materials and Structures (2016) 49: 2563-2580. https://doi.org/10.1617/s11527-015-0668-5

[12] CNR-DT 200 R1/2013, Guide for the Design and Construction of Externally Bonded FRP Systems for Strengthening Existing Structures, Rome, Italy, National Research Council, 2013.

[13] R. Capozucca, Experimental FRP/SRP-historic masonry delamination, Composite Structures (2010) 92: 891-903. https://doi.org/10.1016/i.compstruct.2009.09.029

[14] C.R. Willis, Q. Yang, R. Seracino, M.C. Griffith, Bond behaviour of FRP-to-clay brick masonry joints, Engineering Structures (2009) 31: 2580-2587. https://doi.org/10.1016/j.engstruct.2009.06.006

[15] J. Kashyap, C.R. Willis, M.C. Griffith, J.M. Ingham, M.J. Masia, Debonding resistance of FRP-to-clay brick masonry joints, Engineering Structures (2012) 41: 186-198. https://doi.org/10.1016/j.engstruct.2012.03.032

[16] R. Capozucca, Effects of mortar layers in the delamination of GFRP bonded to historic masonry, Composites: Part B (2013) 44: 639649. https://doi.org/10.1016/j.compositesb.2012.02.012

[17] F.G. Carozzi, P. Colombi, C. Poggi, Calibration of end-debonding strength model for FRP-reinforced masonry, Composite Structures (2015) 120: 366-377. https://doi.org/10.1016/j.compstruct.2014.09.033

[18] A. Napoli, G. de Felice, S. De Santis, R. Realfonzo, Bond behaviour of Steel Reinforced Polymer strengthening systems, Composite Structures (2016) 152: 499-515. https://doi.org/10.1016/j.compstruct.2016.05.052

[19] M.A. Aiello, S.M. Sciolti, Bond analysis of masonry structures strengthened with CFRP sheets, Construction and Building Materials (2006) 20: 90-100. https://doi.org/10.1016/j.conbuildmat.2005.06.040

[20] U.S. Camli, B. Binici, Strength of carbon fiber reinforced polymers bonded to concrete and masonry, Construction and Building Materials (2007) 21: 1431-1446. https://doi.org/10.1016/j.conbuildmat.2006.07.003

[21] C. Faella, G. Camorani, E. Martinelli, S.O. Paciello, F. Perri, Bond behaviour of FRP strips glued on masonry: Experimental investigation and empirical formulation, Construction and Building Materials (2012) 31: 353-363. https://doi.org/10.1016/j.conbuildmat.2011.12.100

[22] R. Fedele, M. Scaioni, L. Barazzetti, G. Rosati, L. Biolzi, Delamination tests on CFRP-reinforced masonry pillars: Optical monitoring and mechanical modeling, Cement and Concrete Composites (2014) 45: 243-254. https://doi.org/10.1016/j.cemconcomp.2013.10.006

[23] E. Grande, M. Imbimbo, E. Sacco, Bond behaviour of CFRP laminates glued on clay bricks: Experimental and numerical study, Composites: Part B (2011) 42: 330-340. https://doi.org/10.1016/j.compositesb.2010.09.020

[24] R. Capozucca, V. Ricci, Bond of GFRP strips on modern and historic brickwork masonry, Composite Structures (2016) 140: 540-555. https://doi.org/10.1016/j.compstruct.2015.12.047

[25] P. Carrara, D. Ferretti, F. Freddi, Debonding behavior of ancient masonry elements strengthened with CFRP sheets, Composites: Part B (2013) 45: 800-810. https://doi.org/10.1016/j.compositesb.2012.04.029

[26] F. Ceroni, A. Garofano, M. Pecce, Bond tests on tuff elements externally bonded with FRP materials, Materials and Structures (2015) 48: 2093-2110. https://doi.org/10.1617/s11527-014-0295-6

[27] C. Mazzotti, B. Ferracuti, A. Bellini, Experimental bond tests on masonry panels strengthened by FRP, Composites Part B (2015) 80: 223-237. https://doi.org/10.1016/j.compositesb.2015.05.019

[28] C. Mazzotti, B. Ferracuti, A. Bellini, Experimental study on masonry panels strengthened by GFRP: the role of inclination between mortar joints and GFRP sheets, Key Engineering Materials (2015) 624: 559-566.

https://doi.org/10.4028/www.scientific.net/KEM.624.559

[29] C. Mazzotti, E. Sassoni, A. Bellini, B. Ferracuti, E. Franzoni, Strengthening of masonry elements by FRP: Influence of brick mechanical and microstructural poperties, Key Engineering Materials (2015) 624: 330-337. https://doi.org/10.4028/www.scientific.net/KEM.624.330

[30] S. Andreotti, E. Sassoni, A. Bellini, B. Mazzanti, M.C. Bignozzi, E. Franzoni, C. Mazzotti, How do brick microstructural and mechanical properties affect GFRP bond strength?, Proc. Structural Analysis of Historical Constructions - SAHC 2016, Van Balen \& Verstrynge (Eds.), Leuven (Belgium), 13-15 September 2016, Taylor \& Francis Group, London, ISBN 978-1-138-02951-4. https://doi.org/10.1201/9781315616995-58

[31] F. Ceroni, A. Kwiecień, C. Mazzotti, A. Bellini, E. Garbin, M. Panizza, M.R. Valluzzi, The role of the adhesive stiffness on the FRP-masonry bond behavior: A round robin inititive, Proc. Structural Analysis of Historical Constructions - SAHC 2016, Van Balen \& Verstrynge (Eds.), Leuven (Belgium), 13-15 September 2016, Taylor \& Francis Group, London, ISBN 978-1-138-02951-4. https://doi.org/10.1201/9781315616995-158

[32] E. Sassoni, S. Andreotti, A. Bellini, B. Mazzanti, M.C. Bignozzi, C Mazzotti, E. Franzoni, Influence of mechanical properties, anisotropy, surface roughness and porosity of brick on FRP debonding force, Composites Part B (2017) 108: 257-269. https://doi.org/10.1016/j.compositesb.2016.10.020

[33] E. Sassoni, V. Sarti, A. Bellini, C. Mazzotti, E. Franzoni, The role of mortar joints in FRP debonding from masonry, Composites Part B (2018) 135: 166-174 https://doi.org/10.1016/j.compositesb.2017.10.021

[34] F. Ceroni, M. Leone, V. Rizzo, A. Bellini, C. Mazzotti, Influence of mortar joints on the behaviour of FRP materials bonded to different masonry substrates, Engineering Structures (2017) 153: 550-568. https://doi.org/10.1016/i.engstruct.2017.10.030

[35] M. Malena, G. de Felice, Debonding of composites on a curved masonry substrate: Experimental results and analytical formulation, Composite Structures (2014) 112: 194-206. https://doi.org/10.1016/j.compstruct.2014.02.004

[36] I. Basilio, R. Fedele, P.B. Lourenço, G. Milani, Assessment of curved FRP-reinforced masonry prisms: Experiments and modeling, Construction and Building Materials (2014) 51: 492-505. https://doi.org/10.1016/j.conbuildmat.2013.11.011

[37] C. Carloni, K.V. Subramaniam, Investigation of the interface fracture during debonding between FRP and masonry, Advances in Structural Engineering (2016) 12: 731-743. https://doi.org/10.1260/136943309789867890

[38] M. Panizza, E. Garbin, M.R. Valluzzi, C. Modena, Experimental study of the bond of FRP applied to natural stones and masonry prisms, Key Engineering Materials (2015) 624: 453-460. https://doi.org/10.4028/www.scientific.net/KEM.624.453

[39] C. Carloni, K.V. Subramaniam, FRP-masonry debonding: numerical and experimental study of the role of mortar joints, Journal of Composites for Construction (2012) 16(5): 581-589. 
https://doi.org/10.1061/(ASCE)CC.1943-5614.0000282

[40] J. Yao, J.G. Teng, J.F. Chen, Experimental study on FRP-to-concrete bonded joints, Composites Part B (2005) 36: 99-113. https://doi.org/10.1016/j.compositesb.2004.06.001

[41] B. Ghiassi, J. Xavier, D.V. Oliveira, P.B. Lourenço, Application of digital image correlation in investigating the bond between FRP and masonry, Composite Structures (2013) 106: 340-349. https://doi.org/10.1016/j.compstruct.2013.06.024

[42] M. Tekieli, S. De Santis, G. de Felice, A. Kwiecień, F. Roscini, Application of Digital Image Correlation to composite reinforcements testing, Composite Structures (2017) 160: 670-688. https://doi.org/10.1016/j.compstruct.2016.10.096

[43] S. De Santis, G. de Felice, A. Napoli, R. Realfonzo, Strengthening of structures with Steel Reinforced Polymers: A state-of-the-art review, Composites Part B (2016) 104: 87-110. https://doi.org/10.1016/j.compositesb.2016.08.025

[44] C. Mazzotti, F.S. Murgo, Numerical and experimental study of GFRP-masonry interface behavior: Bond evolution and role of the mortar layers, Composites Part B (2015) 75: 212-225. https://doi.org/10.1016/j.compositesb.2015.01.034

[45] F. Focacci, C. Carloni, Periodic variation of the transferable load at the FRP-masonry interface, Composite Structures (2015) 129: 90100. https://doi.org/10.1016/i.compstruct.2015.03.008

[46] M. Malena, G. de Felice, Analytical modelling of composite-tomasonry prisms bond, Key Engineering Materials (2015) 624: 567574. https://doi.org/10.4028/www.scientific.net/KEM.624.567

[47] F. Freddi, E. Sacco, Debonding process of masonry element strengthened with FRP, Procedia Engineering (2015) 109: 27-34. https://doi.org/10.1016/j.proeng.2015.06.206

[48] E. Grande, M. Imbimbo, E. Sacco, Modeling and numerical analysis of the bond behavior of masonry elements strengthened with SRP/SRG, Composites Part B (2013) 55:128-138. https://doi.org/10.1016/j.compositesb.2013.06.003

[49] B. Ghiassi, D.V. Oliveira, P.B. Lourenço, G. Marcari, Numerical study of the role of mortar joints in the bond behavior of FRPstrengthened masonry, Composites Part B (2013) 46: 21-30. https://doi.org/10.1016/j.compositesb.2012.10.017

[50] Ö. Anil, C. Durucan, S.W. Din, Experimental study on the stress distribution at the interface between CFRP and three different types of masonry units, Composites Part B (2016) 92: 63-73. https://doi.org/10.1016/j.compositesb.2016.02.026

[51] C. Mazzotti, M. Savoia, B. Ferracuti, A new single-shear set-up for stable delamination tests on FRP-concrete joints, Construction and Building Materials (2009) 23(4): 1529-1537. https://doi.org/10.1016/j.conbuildmat.2008.04.003

[52] M. Savoia, B. Ferracuti, L. Vincenzi, Inverse analysis for the analysis of FRP-concrete interface law, Adv Sruct Eng (2009) 12(5): 613-625. https://doi.org/10.1260/136943309789867845

[53] B. Ferracuti, M. Savoia, C. Mazzotti, Interface law for FRP-concrete delamination, Composite Structures (2007) 80: 523-531. https://doi.org/10.1016/j.compstruct.2006.07.001

[54] C. Carloni, F. Focacci, FRP-masonry interfacial debonding: An energy balance approach to determine the influence of mortar joints, European Journal of Mechanics A/Solids (2016) 55: 122-133. https://doi.org/10.1016/j.euromechsol.2015.08.003

[55] Y. Su, C. Wu, M.C. Griffith, Modelling of the bond-slip behavior in FRP reinforced masonry, Construction and Building Materials (2011) 25: 328-334 https://doi.org/10.1016/i.conbuildmat.2010.06.021

[56] M. Malena, F. Focacci, C. Carloni, G. de Felice, The effect of the shape of the cohesive material law on the stress transfer at the FRP-masonry interface, Composites Part B (2017) 110: 368-380. https://doi.org/10.1016/j.compositesb.2016.11.012

[57] R. Fedele, G. Milani, Three-dimensional effects induced by FRPfrom-masonry delamination, Composite Structures (2011) 93: 1819-1831. https://doi.org/10.1016/j.compstruct.2011.01.022

[58] R. Fedele, G. Milani, Assessment of bonding stresses between FRP sheets and masonry pillars during delamination tests, Composites Part B (2012) 43: 1999-2011. https://doi.org/10.1016/j.compositesb.2012.01.080

[59] F. Freddi, E. Sacco, An interphase model for the analysis of the masonry-FRP bond, Composite Structures (2016) 138: 322-334. https://doi.org/10.1016/i.compstruct.2015.11.041

[60] R. Fedele, G. Milani, A numerical insight into the response of masonry reinforced by FRP strips. The case of perfect adhesion, Composite Structures (2010) 92: 2345-2357. https://doi.org/10.1016/i.compstruct.2010.03.014
[61] B. Ghiassi, G. Marcari, D.V. Oliveira, P.B. Lourenço, Numerical analysis of bond behavior between masonry bricks and composite materials, Engineering Structures (2012) 43: 210-220. https://doi.org/10.1016/j.engstruct.2012.05.022

[62] E. Grande, M. Imbimbo, A simple 1D-Finite Element approach for the study of the bond behavior of masonry elements strengthened by FRP, Composites Part B (2016) 91: 548-558. https://doi.org/10.1016/j.compositesb.2016.02.005

[63] C. Maruccio, I. Basilio, D.V. Oliveira, P.B. Lourenço, G. Monti, Numerical modelling and parametric analysis of bond strength of masonry members retrofitted with FRP, Construction and Building Materials (2014) 73: 713-727. https://doi.org/10.1016/i.conbuildmat.2014.09.082

64] F. Ceroni, A. Garofano, M. Pecce, Modelling of the bond behaviour of tuff elements externally bonded with FRP sheets, Composites Part B (2014) 59: 248-259. https://doi.org/10.1016/i.compositesb.2013.12.007

[65] K.V. Subramaniam, C. Carloni, L. Nobile, Width effect in the interface fracture energy during shear debonding of FRP sheets from concrete, Engineering Fracture Mechanics (2007): 74: 578594. https://doi.org/10.1016/i.engfracmech.2006.09.002

[66] A. Cottone, G. Giambianco, Minimum bond length and size effects in FRP-substrate bonded joints, Engineering Fracture Mechanics (2009) 76: 1957-1976. https://doi.org/10.1016/i.engfracmech.2009.05.007

[67] L. De Lorenzis, G. Zavarise, Debonding analysis of thin plates from curved substrates, Engineering Fracture Mechanics (2010) 77: 3310-328. https://doi.org/10.1016/j.engfracmech.2010.08.013

[68] A. Caporale, L. Feo, D. Hui, E. Luciano, Debonding of FRP in multispan masonry arch structures via limit analysis, Composite Structures (2014) 108: 856-865. https://doi.org/10.1016/i.compstruct.2013.10.006

[69] O. Holzenkämpfer, Ingenieurmodelle des verbundes geklebter bewehrung für betonbauteile (in German), Ph.D. thesis, Braunschweig, Germany, University of Braunschweig, 1994.

[70] K. Brosens, D. Van Gemert, Anchorage design for externally bonded carbon fiber reinforced polymer laminates, Proc. FRPRCS4 International Symposium, Baltimore (USA), November 1999.

[71] J.F. Chen, J.G. Teng, Anchorage strength models for FRP and steel plates bonded to concrete, J Struct Eng ASCE (2001) 127: 784 791.https://doi.org/10.1061/(ASCE)0733-9445(2001)127:7(784)

[72] J.G. Teng, J.Yao, Plate end debonding in FRP-plated RC beams - II: Strength model, Engineering Structures (2007) 29: 2472-2486 https://doi.org/10.1016/i.engstruct.2006.11.023

[73] H. Toutanji, P. Saxena, L. Zhao, T. Ooi, Prediction of interfacial bond failure of FRP-concrete surface, ASCE Journal of Composites for Construction (2007) 11(4): 427-436. https://doi.org/10.1061/(ASCE)1090-0268(2007)11:4(427)

[74] I. Mansouri, O. Kisi, Predicition of debonding strength for masonry elements retrofitted with FRP composites using neuro fuzzy and neural network approaches, Composites Part B (2015) 70: 247-255. https://doi.org/10.1016/i.compositesb.2014.11.023

[75] P. Carrara, F. Freddi, Statistical assessment of a design formula for the debonding resistance of FRP reinforcements externally glued on masonry units, Composites Part B (2014) 66: 65-82. https://doi.org/10.1016/j.compositesb.2014.04.032

[76] JSCE, Recommendations for upgrading of concrete structures with use of continuous fiber sheets, Japan Society of Civil Engineers, Concrete Engineering Series, Tokyo, Japan, 2001.

[77] $\mathrm{ACl} 440.2 \mathrm{R}-08$, Guide for the design and construction of externally bonded FRP systems for strengthening concrete structures, Farmington Hills, Michigan, American Concrete Institute, 2008.

[78] FIB Bulletin 14 - Externally bonded FRP reinforcement for RC structures, Lausanne, Switzerland, Fèdèration International du Bèton, 2001.

[79] F. Bencardino, A. Condello, Reliability and adaptability of the analytical models proposed for the FRP systems to the Steel Reinforcement Polymer and Steel Reinforced Grout strengthening systems, Composites Part B (2015) 76: 249-259. https://doi.org/10.1016/j.compositesb.2015.02.029

[80] F. Ceroni, B. Ferracuti, M. Pecce, M. Savoia, Assessment of a bond strength model for FRP reinforcement externally bonded over masonry blocks, Composites Part B (2014) 61: 147-161. https://doi.org/10.1016/j.compositesb.2014.01.028

[81] F. Ceroni, B. Ferracuti, M. Pecce, M. Savoia, Corrigendum to "Assessment of a bond strength model for FRP reinforcement externally bonded over masonry blocks" [Compos. Part B: Eng. 61 
(2014) 147-161], Composites Part B (2015) 69: 612. https://doi.org/10.1016/j.compositesb.2014.08.053

[82] E.Y. Sayed-Ahmed, R. Bakay, N.G. Shrive, Bond strength of FRP laminates to concrete: state-of-the art review, J Struct Eng (2009) 9: 45-61.

[83] T. D'Antino, C. Pellegrino, Bond between FRP composites and concrete: assessment of design procedures and analytical models, Composites Part B (2014) 60: 440-456.

https://doi.org/10.1016/j.compositesb.2013.12.075

[84] A. Khalifa, W.J. Gold, A. Nanni, M.I. Abdel Aziz, Contribution of externally bonded FRP to shear capacity of RC flexural members, J Compos Construct (1998) 2: 195-202. https://doi.org/10.1061/(ASCE)1090-0268(1998)2:4(195)

[85] R. Niedermeier, Stellungnahme zur richhtlinie für das verkleben von betonbautelien durch ankleben von stahllaschen (in German), Munich, Germany, University of Munich, 1996. 